\title{
A avaliação formativa no ensino superior: o contributo do feedback interativo e construtivo na aprendizagem ativa dos estudantes
}

\author{
Formative assessment in higher education: the contribution of interactive and \\ constructive feedback on students' active learning
}

\section{La evaluación formativa en la enseñanza superior: el aporte de la retroalimentación interactiva en el aprendizaje activo de los estudiantes}

\author{
Susana Oliveira e Sál \\ Maria Palmira Alves ${ }^{2}$ \\ António Pedro Costa ${ }^{3}$ \\ http://dx.doi.org/10.5216/31821
}

\begin{abstract}
Resumo
Neste artigo, apresentam-se os principais resultados de uma investigação, que teve como principal objetivo analisar a importância do feedback como estratégia de avaliação formativa e de melhoria do desempenho dos estudantes. O objeto de estudo foi uma unidade curricular (UC) integrada no currículo de Mestrado Integrado em Psicologia, numa Instituição de Ensino Superior. Observámos $20 \mathrm{~h}$ de aulas, no $2^{\circ}$ semestre de 2013/2014 e realizámos uma entrevista semiestruturada ao docente que lecionou a UC e uma entrevista focus group a 5 estudantes que a frequentaram. Os dados foram analisados e categorizados com recurso ao webQDA- Software de Apoio à Análise Qualitativa. O feedback, interativo e construtivo, promovia o envolvimento dos estudantes na acomodação dos seus processos cognitivos, ajudando-os a desenvolver competências de regulação, ao mesmo tempo que promovia uma aprendizagem consistente. $\mathrm{O}$ docente criava ambientes de aprendizagem dinâmicos e não ameaçadores, estimulava a participação, a partilha, a colaboração, a exposição pessoal e a crítica construtiva. Em contextos similares de avaliação formativa, o recurso pelo docente e pelos estudantes ao feedback construtivo e interativo deve ser uma estratégia de regulação para a melhoria e consolidação da aprendizagem.
\end{abstract}

Palavras-chave: Ensino Superior. Avaliação formativa. Feedback interativo e construtivo.

\begin{abstract}
In this article, we present the main results of a research, which aimed at analyzing the importance of feedback as a strategy of formative assessment, as well as its relevance in improving students' performances. The object of study was a curricular unit (CU) integrated in the curriculum of a Master in Psychology, in a Higher Education Institution. On the 2nd semester of 2013/2014, twenty hours of classes were observed and we conducted a semi structured interview with the teacher who taught the $\mathrm{CU}$ and a focus group interview with five students. Data was analyzed and categorized using the webQDA- Software Support Qualitative Analysis. The feedback, interactive and constructive, promoted students' involvement in the accommodation of their cognitive processes, helping them to

\footnotetext{
1 Mestre em Educação, especialidade em supervisão pedagógica e doutoranda em Educação na especialidade desenvolvimento curricular e avaliação. Investigadora do CIED - Centro de Investigação em Educação da Universidade do Minho. Portugal, Braga. E-mail: susanaemiliasa@gmail.com

${ }^{2}$ Professora Doutora. Auxiliar do IE - Instituto de Educação da Universidade do Minho na área desenvolvimento curricular e avaliação e membro integrado do CIED - Centro de Investigação em Educação da Universidade do Minho. Portugal, Braga. E-mail: palves@ie.uminho.pt

${ }^{3}$ Professor Doutor. Auxiliar no do ISLA - Instituto Politécnico de Gestão e Tecnologia, Universidade de Aveiro e membro integrado do CIDTFF- Centro de Investigação Didática e Tecnologia na Formação de Formadores da Universidade de Aveiro. Portugal, Aveiro. E-mail: pcosta@ludomedia.pt
} 
develop self-regulatory skills, while promoting a consistent learning. The teacher created a dynamic and non-threatening learning environment, encouraged participation, collaboration, sharing, personal exposure and constructive criticism among students. In similar contexts of formative assessment, the use of interactive and constructive feedback by teachers and students should be encouraged as a strategy of regulation for the improvement and consolidation of learning.

Keywords: Higher Education. Formative assessment. Interactive and constructive feedback.

\section{Resumen}

En este artículo, presentamos los principales resultados de una investigación, en el campo de las ciencias de educación, cuyo objetivo fundamental fue analizar la importancia de la retroalimentación como estrategia de la evaluación formativa para mejorar el desempeño de los estudiantes. El objeto de estudio fue una unidad curricular (UC) integrado en el plan de estudios de un Máster en Psicología, de una institución de enseñanza superior. Observamos 20 horas de clases, durante el segundo semestre de 2013/14 y efectuamos una entrevista semiestructurada al docente que impartió la unidad curricular, e una entrevista en grupos de discusión a cinco estudiantes que asistían a las clases. Los datos fueron analizados y clasificados con la ayuda de lo webQDA- Software de apoyo a Análisis Cualitativas. La retroalimentación, interactiva y constructiva, promovía la participación de los estudiantes en la adaptación de sus procesos cognitivos, ayudándolos a desarrollar competencias de autorregulación, al mismo tiempo que originaba un aprendizaje consistente. El profesor creaba ambientes de aprendizajes dinámicos y no amenazadores, estimulaba la participación, intercambio, colaboración, la exposición personal y la crítica constructiva. En contextos similares de evaluación formativa, la utilización tanto por docentes como por estudiantes de la retroalimentación constructiva e interactiva debe ser una estrategia de autorregulación para la mejoría y consolidación del aprendizaje.

Palabras clave: Enseñanza Superior. Evaluación formativa. Retroalimentación interactiva y constructiva.

\section{INTRODUÇÃ̃O}

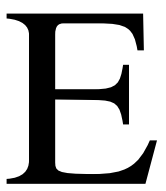

m Portugal, com praticamente 13 anos decorridos da assinatura da Declaração de Bolonha, as Instituições de Ensino Superior (IES) reformularam-se práticas de ensino, de avaliação e, fundamentalmente, de aprendizagens, de acordo com a mudança de paradigma educacional, que defende a troca de informação e conhecimento, equivalência de graus e mobilidade de estudantes e docentes no Espaço Europeu do Ensino Superior. Seja como resultado da iniciativa das próprias IES, seja para concretizar a orientação de instituições como a European University Association, que promove o Institutional Evaluation Programme, têm sido alteradas as práticas de ensino e de aprendizagem, no sentido de promover uma aprendizagem ativa. Mas, a alteração de práticas de ensino e de aprendizagem requer, inevitavelmente, a alteração das formas de avaliar. Para vários autores (STUFFLEABEAM \& SHINKFIELD, 1987; STRUYVEN, DOCHY \& JANSSENS, 2005; ALVES, 2004), há modalidades de avaliação que contribuem significativamente para a melhoria da qualidade da aprendizagem. 
De entre estas modalidades, destaca-se a avaliação formativa e um dos seus elementos caraterísticos, o feedback interativo e construtivo, que pode ser uma estratégia de avaliação promotora de aprendizagem ativa (BELL \& COWIE, 2000; BIGGS \& TANG, (2007); HIGGINS, HARTLEY \& SKELTON, 2002; NICOL \& MACFARLANE - DICK, 2006; YORKE, 2003; OLIVEIRA, 2009).

\subsection{Aprendizagem ativa}

Para Oliveira (2009) é contestável a ideia comum que muitos docentes têm do conceito de aprendizagem ativa como bastando o estudante estar a ouvir uma explicação do docente ou estar a ver a resolução de um exercício efetuada pelo docente. Pelo contrário, a aprendizagem ativa engloba um conjunto de atividades bem mais complexas. Assim, como sustentam Bonwell e Eison (1991), na aprendizagem ativa, os estudantes estão envolvidos em tarefas de elevado grau cognitivo, tais como, análise, síntese, avaliação, não se limitando a ouvir; o ensino centra- se menos na transmissão de informação e a atenção é dada ao desenvolvimento de competências dos estudantes, tendo em consideração os seus valores e atitudes. Além disso, o docente terá de "multiplicar as situações de avaliação, jogando com as interações alunos-professores, alunos-alunos, mas também alunos-material didático" (ALVES, 2004, p.61). Neste contexto, é incontornável usar formas de avaliação adaptadas ao sistema de aprendizagem ativa, numa lógica de motivação do acompanhamento e da autorregulação.

\subsection{Avaliação formativa}

A avaliação formativa é uma modalidade de avaliação a privilegiar numa dinâmica de aprendizagem ativa, uma vez que, havendo mais informação, uma recolha mais ampla de dados sobre a aprendizagem está disponível.

Entendemos por avaliação formativa toda a prática contínua de avaliação, cuja finalidade principal é a melhoria dos processos de ensino e de aprendizagem, através de um processo de regulação permanente. Esta forma de avaliar recolhe informação que serve para que os estudantes possam aprender mais e/ou corrigir os seus erros e para que os docentes possam aprender a trabalhar melhor, ou seja, a aperfeiçoar a sua prática docente (NUÑO, 2012).

Neste contexto, para avaliar é "indispensável criar mecanismos de acompanhamento do processo para o ir entendendo, acertando e orientando no sentido desejado" (ROLDÃO, 2003, p. 41). Alves (2004) acrescenta que a avaliação formativa é essencialmente reguladora, situando-a em dois níveis específicos: ao nível da regulação do dispositivo pedagógico e ao 
nível da regulação da atividade do estudante. No primeiro nível, o docente recebe um feedback do impacto do seu trabalho pedagógico e "modifica a ação justificando as suas intervenções", no segundo nível, esta regulação funciona como um indicador que informa o estudante das dificuldades encontradas ao longo do processo de formação, "a fim de reconhecer e de corrigir os erros" (ALVES, 2004, p. 61).

\subsection{0 feedback interativo e construtivo}

O feedback é um dos elementos caraterísticos da avaliação formativa, sendo um meio de comunicação privilegiado para que o estudante possa avaliar o seu progresso (PERRENOUD, 1999; HADJI, 1994; DREW, 2001; BIGGS, 2003; FERNANDES, 2006; HOUNSELL, 2007).

No contexto da aprendizagem ativa, "dar feedback" é enviar mensagens de retorno, com sentido bidirecional, dos docentes para os estudantes e vice versa, com a finalidade de obter melhorias no processo, normalmente designado na literatura por feedback interativo (TORRANO \& GONZÁLEZ, 2004; HOUNSELL, 2007).

As mensagens de retorno ou feedback dos docentes para os estudantes, tendo em vista a regulação das suas atividades académicas, são usadas pelos estudantes para fazer melhorias posteriores. O feedback dos estudantes para os docentes é usado para regular as práticas e metodologias de ensino-aprendizagem em sala de aula, numa lógica reflexiva.

Segundo Yorke (2003), o feedback pode ser formal e informal. O feedback informal é normalmente dado de forma oral, em conversa com o estudante ou grupo de estudantes, mas também pode ser dado por e-mail ou na participação em fóruns, quando o docente dá uma resposta na discussão para estimular a participação ou direcionar a discussão. O feedback formal é dado nas avaliações previstas na planificação das disciplinas onde o desempenho dos estudantes pode ser "medido".

O feedback construtivo é predominantemente descritivo e não valorativo, apontando o que faltou e o que poderia ser feito de outra forma (ASKEW \& LODGE, 2000).

Segundo Alarcão, Leitão e Roldão (2009, p.6), o feedback construtivo, nomeadamente co-construtivo, enquadra-se numa dialógica preponderante de questionamento e de reflexão, “...feedbacks orientadores da acção e do pensamento de um modo interactivo, dialógico, o qual ajuda a compreender o que se faz e se observa através do questionamento e da reflexão conjuntas e que designaremos como feedback co-construtivo". Neste sentido, utiliza-se o feedback para os estudantes numa lógica de questionamento, quer como 
esclarecimento de dúvidas, quer como crítica estimuladora, de apoio, de recomendação, de síntese ou de esclarecimento concetual, teórico ou metodológico.

A eficiência do feedback depende, essencialmente, da sua oportunidade, da sua especificidade e individualidade, da sua objetividade e consistência. Um feedback eficiente, interativo e construtivo promove o desempenho das aprendizagens dos estudantes (TORRANO \& GONZÁLEZ, 2004).

\section{OPÇÕES METODOLÓGICAS}

O estudo foi norteado pelas seguintes questões: em que medida a utilização do feedback faz parte da vida pedagógica das salas de aula? De que modo os docentes e os estudantes utilizam o feedback? Qual a natureza e a frequência do feedback usado nas aulas, quer por docentes quer pelos estudantes?

Foram observadas 20 horas de aulas, numa UC do plano curricular do $2^{\mathbf{o}}$ ciclo de um Mestrado Integrado em Psicologia, com 70 estudantes e com a taxa de $100 \%$ de aprovação. As aulas tinham a duração de duas horas, uma vez por semana e decorriam numa sala em anfiteatro.

A observação foi feita pela investigadora que, numa reunião prévia com a docente da UC, acordou os procedimentos metodológicos a seguir na observação de aulas. Seguidamente, foi clarificado, junto dos estudantes, o motivo da sua presença na sala de aula, de modo a ser "ignorada" a sua presença, a fím de não ser um elemento perturbador do normal funcionamento das aulas. Adotámos um comportamento discreto, não intrusivo e não participativo.

A UC tinha a duração de 20 semanas (1 semestre) e caracterizava-se por uma formação transversal e abrangente, focada em problemas e questões em vários domínios da Ciência Aplicada, em que a análise de um tema era estimulada sob diversas óticas ${ }^{4}$. $\mathrm{O}$ ensino era orientado para a aprendizagem numa lógica de natureza profissionalizante, dando relevância à atividade do estudante na construção do seu conhecimento e no desenvolvimento das competências. O docente disponibilizava-se, quer presencialmente, quer a distância, para apoiar os estudantes. A avaliação era contínua, com função de regulação e monitorização.

Os registos foram feitos numa grelha de observação de aulas, adaptada das dimensões de um projeto de investigação: Avaliação, Ensino e Aprendizagem no Ensino Superior $(\mathrm{AVENA})^{5}$, cujo referencial teórico listava três dimensões: ensino, avaliação e aprendizagem.

\footnotetext{
${ }^{4}$ Programa curricular da UC fornecido pelo docente.

${ }^{5}$ Projeto FCT Avaliação, Ensino e Aprendizagens No Ensino Superior em Portugal e no Brasil: Realidades e Perspectivas (AVENA) (PTDC/CPE-CED/114318/2009). Este projeto engloba 4 IES portuguesas: Universidade de Lisboa, Universidade do Minho, Universidade de Coimbra e Universidade de Évora; e, 3 IES brasileiras: Universidade do Estado do Pará, Universidade da Amazónia e Universidade de São Paulo.
} 
A cada dimensão estavam associadas categorias e os aspetos a observar. Neste artigo, apenas apresentamos e discutimos os dados relativos à dimensão avaliação e à categoria natureza, frequência e distribuição do feedback, tal como se apresenta no Quadro 1.

Quadro 1- Matriz da grelha de observação de aulas

\begin{tabular}{|l|l|ll|}
\hline \multicolumn{1}{|c|}{ Dimensão } & \multicolumn{1}{|c|}{ Categoria } & \multicolumn{1}{c|}{ Aspetos a observar } \\
\hline & $\begin{array}{l}\text { Natureza, frequência } \\
\text { distribuição do feedback }\end{array}$ & e & Que tipo de feedback é dado pelo docente? \\
& & - Com que frequência existe feedback? & Sobre que tarefas/atividades? \\
& & - Existe discussão dos resultados da avaliação? & Como reagem os estudantes ao processo de avaliação? (linguagem verbal e não- \\
& & & $\begin{array}{l}\text { verbal, autoestima, motivação/desmotivação); } \\
\text { Como reagem os estudantes aos resultados da avaliação? (linguagem verbal e }\end{array}$ \\
& & não-verbal, autoestima, motivação/desmotivação); \\
\hline
\end{tabular}

No final da observação, para conhecer as perspetivas do docente e dos estudantes sobre o processo de avaliação observado, realizámos uma entrevista semiestruturada ao docente, que codificámos por D e uma entrevista focus group a 5 estudantes, que codificámos por E, cujo conteúdo foi gravado, transcrito ipsis verbis e, seguidamente, sujeito a análise de conteúdo (BARDIN, 2011). Quer o docente, quer os estudantes, validaram o conteúdo das entrevistas.

Os registos da grelha de observação das 20 horas de aulas, assim como todas as notas que a observadora tomava deram origem a uma narrativa. Estes dados foram triangulados com os das entrevistas, de acordo com a categorização (BARDIN, 2011; AMADO, COSTA \& CRUSOÉ, 2013), recorrendo ao software de investigação qualitativa webQDA (SOUZA, COSTA \& MOREIRA, 2011), tal como se apresenta na Figura 1.

Figura 1 - Fases da análise de dados

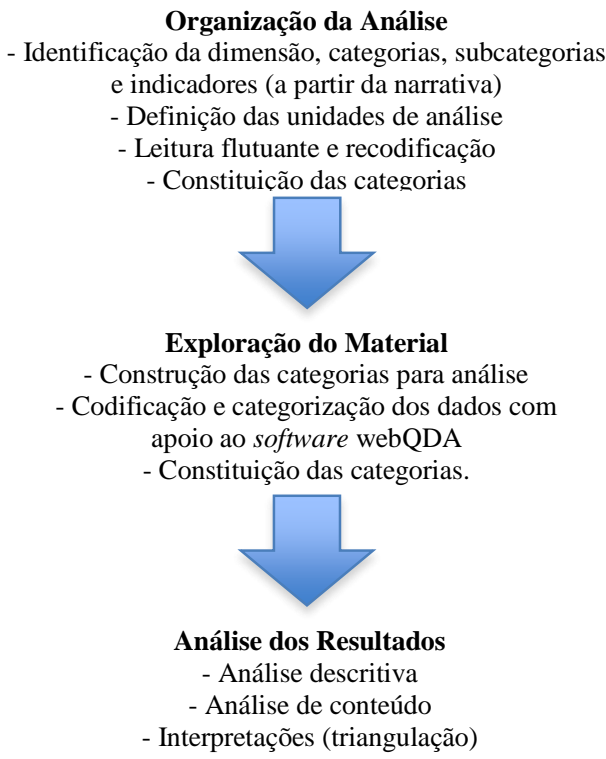

Fonte: adaptado de AMADO et al., 2013; COSTA, 2012. 
À categoria natureza, frequência e distribuição do feedback, foi acrescentada uma nova categoria, que emergiu na análise dos dados, que designamos por utilização do feedback (ALARCÃO et al., 2009). Na Tabela 1 são apresentadas as categorias, subcategorias e definiç̧ões do feedback.

Tabela 1 - Categorias, subcategorias e definições do feedback

\begin{tabular}{|c|c|c|}
\hline Categorias & Subcategorias & Definições \\
\hline \multirow{6}{*}{$\begin{array}{l}\text { Natureza, } \\
\text { frequência e } \\
\text { distribuição } \\
\text { do feedback }\end{array}$} & Oral e Informal & $\begin{array}{l}\text { Respostas geradas numa discussão para estimular a } \\
\text { participação ou direcionar a discussão. }\end{array}$ \\
\hline & Escrito e Formal & $\begin{array}{l}\text { Comentários efetuados nas avaliações previstas na } \\
\text { planificação das disciplinas onde o desempenho dos } \\
\text { estudantes pode ser "medido". }\end{array}$ \\
\hline & Muito frequente & $\begin{array}{l}\text { Comentários que indiciem uma frequência elevada de } \\
\text { feedback. }\end{array}$ \\
\hline & Pouco frequente & $\begin{array}{l}\text { Comentários que indiciem uma frequência diminuta de } \\
\text { feedback. }\end{array}$ \\
\hline & $\begin{array}{l}\text { Atividades de } \\
\text { sala de aula }\end{array}$ & $\begin{array}{l}\text { A interpelação acerca da estratégia, organização, } \\
\text { prioridades, diretivas ou descrição da atividade de sala } \\
\text { de aula. }\end{array}$ \\
\hline & $\begin{array}{l}\text { Atividades fora } \\
\text { de sala aula }\end{array}$ & $\begin{array}{l}\text { A interpelação acerca da estratégia, organização, } \\
\text { prioridades, diretivas ou descrição da atividade fora da } \\
\text { sala de aula. }\end{array}$ \\
\hline \multirow[t]{6}{*}{$\begin{array}{l}\text { Utilização do } \\
\text { feedback }\end{array}$} & $\begin{array}{l}\text { Questionamento } \\
\text { como } \\
\text { esclarecimento } \\
\text { de dúvidas }\end{array}$ & $\begin{array}{l}\text { Interpelações cujas respostas sejam de natureza } \\
\text { descritiva ou explicativa. }\end{array}$ \\
\hline & $\begin{array}{l}\text { Questionamento } \\
\text { crítico ou } \\
\text { estimulador }\end{array}$ & $\begin{array}{l}\text { Interpelações cujas respostas sejam de natureza crítico- } \\
\text { reflexiva. }\end{array}$ \\
\hline & $\begin{array}{l}\text { Apoio/encoraja } \\
\text { mento }\end{array}$ & $\begin{array}{l}\text { Expressões de incentivo, de encorajamento ou de } \\
\text { apoio. }\end{array}$ \\
\hline & Recomendação & $\begin{array}{l}\text { Expressões que denotem alternativas, hipóteses, } \\
\text { argumentações ou aprofundamentos. }\end{array}$ \\
\hline & Síntese/Balanço & $\begin{array}{l}\text { Expressões que denotem tendências, conclusões, } \\
\text { sínteses, aspetos a melhorar e evoluções. }\end{array}$ \\
\hline & Esclarecimento & $\begin{array}{l}\text { Expressões que denotem a clarificação, a } \\
\text { reconfiguração, o simplificar concetual, a visibilidade } \\
\text { prática de conceitos teóricos ou vice versa. }\end{array}$ \\
\hline
\end{tabular}

Fonte: dados da pesquisa

A categoria, natureza, frequência e distribuição do feedback, foi dividida nas subcategorias: oral e informal, quando as respostas eram geradas numa discussão para estimular a participação ou direcionar a discussão; escrito e formal, quando os comentários efetuados nas avaliações previstas na planificação das disciplinas onde o desempenho dos estudantes pode ser "medido"; muito frequente e pouco frequente, quando o feedback é expresso com termos de frequência elevada ou diminuta, respetivamente; discussão de 
resultados, se as respostas ou comentários se direcionavam para a contribuição, síntese e análise de resultados experimentais; atividades de sala de aula, se a interpelação é acerca da estratégia, organização, prioridades, diretivas ou descrição da atividade de sala de aula; atividades fora de sala aula, se a interpelação é acerca da estratégia, organização, prioridades, diretivas ou descrição da atividade fora da sala de aula.

A categoria, utilização do feedback, subdivide-se em questionamento como esclarecimento de dúvidas, quando existam interpelações cujas respostas eram de natureza descritiva ou explicativa; questionamento crítico ou estimulador, quando existiam interpelações cujas respostas eram de natureza crítico-reflexiva; apoio ou encorajamento, quando existam expressões de incentivo, de encorajamento ou de apoio; recomendação, quando as expressões denotavam alternativas, hipóteses, argumentações ou aprofundamentos; síntese ou balanço, quando as expressões denotavam tendências, conclusões, sínteses, aspetos a melhorar e evoluções; esclarecimento, quando as expressões denotavam a clarificação, a reconfiguração, a simplificação concetual, a visibilidade prática de conceitos teóricos ou viceversa.

\section{APRESENTAÇÃO E DISCUSSÃO DOS RESULTADOS}

Apresentam-se e discutem-se, de seguida, os dados obtidos a partir da triangulação das fontes de recolha de dados.

Ao longo da discussão dos resultados, utilizamos o termo referências para designar as unidades de registo que podem ser a frase ou conjunto de palavras que façam sentido e tenham significado.

Apresentamos, na Tabela 2, a matriz referente à natureza e frequência do feedback por parte do docente e dos estudantes.

Tabela 2 - Natureza e frequência do feedback (docente e estudantes)

\begin{tabular}{|c|c|c|}
\hline $\begin{array}{c}\text { Natureza do } \\
\text { feedback }\end{array}$ & $\begin{array}{c}\text { Estudantes } \\
\text { (referências) }\end{array}$ & $\begin{array}{c}\text { Docente } \\
\text { (referências) }\end{array}$ \\
\hline Oral e Informal & 9 & 35 \\
\hline Escrito e Formal & 0 & 1 \\
\hline
\end{tabular}

Fonte: dados da pesquisa

O feedback era de natureza construtiva, usado oral e informalmente, sendo mais frequente a sua utilização pelo docente (35 referências). Exemplos de feedback observado: "vê-se logo que estudou”, "perfeito". Relativamente aos estudantes assinalámos 9 referências: "está bem assim", "percebe-se bem". 
O feedback escrito e formal foi observado na apresentação de um trabalho que consistia na elaboração de duas questões por estudante. Só uma das questões foi comentada na aula, tendo o que o docente solicitado aos estudantes o envio da outra por e-mail, uma vez que não tinham tido tempo para terminar na sala de aula. Na aula seguinte, o docente projetou à turma uma sistematização das questões recebidas, com o seguinte comentário: "argumentação muito completa (...)".

Apresentamos, na Tabela 3, a matriz da distribuição do feedback pelo docente e pelos estudantes.

Tabela 3 - Distribuição do feedback (docente e estudantes)

\begin{tabular}{|l|c|c|}
\hline \multicolumn{1}{|c|}{$\begin{array}{c}\text { Distribuição do } \\
\text { feedback }\end{array}$} & $\begin{array}{c}\text { Estudantes } \\
\text { (referências) }\end{array}$ & $\begin{array}{c}\text { Docente } \\
\text { (referências) }\end{array}$ \\
\hline $\begin{array}{l}\text { Atividades de sala de } \\
\text { aula }\end{array}$ & 6 & 32 \\
\hline $\begin{array}{l}\text { Atividades fora de } \\
\text { sala de aula }\end{array}$ & 2 & 6 \\
\hline
\end{tabular}

Fonte: dados da pesquisa

O feedback era distribuído essencialmente pelas tarefas dentro e fora da sala de aula, sendo mais frequente nas atividades de sala de aula, verificado espontaneamente quer pelos estudantes (6 referências), por exemplo, "leste o texto? Tens a certeza? Não parece", quer pelo docente (32 referências), “estejam à vontade, não é para avaliação, é só para produção de conhecimento".

No que diz respeito às atividades realizadas fora de sala de aula, a distribuição do feedback pelo docente registámos (6 referências) . A título de exemplo: “deveriam ter lido melhor este artigo", "essa análise deveria ter sido realizada em grupo". O feedback distribuído pelos estudantes (2 referências) foi, por exemplo, "mandaste-me por e-mail o texto incompleto", "este resumo deu muita ajuda".

Apresentamos, na Tabela 4, a utilização do feedback, quer pelo docente, quer pelo estudante.

Tabela 4 - Utilização do feedback (docente e estudantes)

\begin{tabular}{|l|c|c|}
\hline Utilização do feedback & $\begin{array}{c}\text { Estudantes } \\
\text { (referências) }\end{array}$ & $\begin{array}{c}\text { Docente } \\
\text { (referências) }\end{array}$ \\
\hline $\begin{array}{l}\text { Questionamento como } \\
\text { pedido de } \\
\text { esclarecimento }\end{array}$ & 1 & 2 \\
\hline $\begin{array}{l}\text { Questionamento crítico } \\
\text { ou estimulador }\end{array}$ & 4 & 12 \\
\hline
\end{tabular}




\begin{tabular}{|l|c|c|}
\hline Apoio/encorajamento & 2 & 12 \\
\hline Recomendação & 3 & 5 \\
\hline Síntese/Balanço & 2 & 4 \\
\hline Esclarecimento & 0 & 4 \\
\hline
\end{tabular}

Fonte: dados da pesquisa

O feedback era utilizado pelo docente no questionamento crítico ou estimulador (12 referências), "não se pode inferir isso - ... qual o caminho que deveria seguir?", no apoio ou encorajamento (12 referências), "sabem que conseguem ... se seguirem essa linha de raciocínio". Do mesmo modo, os estudantes usavam feedback de questionamento crítico ou estimulador (4 referências), “pode-se tirar essa conclusão?”, “posso tirar uma dúvida?”, ou de recomendação aos pares (3 referências), "leste o artigo completo", uma vez que as tarefas de sala de aula implicavam, muitas vezes, a organização de uma apresentação oral de um trabalho realizado em grupo.

Observou-se a utilização do feedback no questionamento como pedido de esclarecimento por parte do docente (12 referências), "Por que sugeriu essa metodologia?”, “... não acha que seria menos trabalhoso se seguisse ...?". Do mesmo modo, os estudantes usaram o feedback de questionamento como pedido de esclarecimento ao docente, a propósito de uma atividade para realizar na sala de aula, individualmente, "se nem todos temos computador aqui não poderemos recorrer aos textos de apoio que enviou por e-mail. Como podemos fazer?”.

A utilização do feedback de síntese ou de balanço por parte do docente (4 referências), foi observada quando se proporcionava a realização de um resumo da apresentação à turma de um trabalho de grupo, por exemplo, "defenderam a ... (filosofia) de investigação e está perfeito, mas seria interessante reformularem a questão de investigação à luz da ...". Enquanto os estudantes utilizaram o feedback de síntese (2 referências) na realização de um trabalho de grupo, "agora temos de formular as hipóteses para completar...", “assim não estamos a seguir esta ... metodologia de investigação".

O feedback de esclarecimento apenas foi observado no docente (4 referências), por exemplo "o que se pretende é formular dois objetivos para a questão de investigação".

Observou-se a utilização do feedback de recomendação, quer pelo docente (5 referências), "têm de ler o artigo ... para poder fundamentar", quer pelos estudantes (3 referências), "em vez de formulares os objetivos e depois as questões, devias fazer o contrário". 
Em síntese, o feedback era prática quotidiana do ambiente pedagógico na sala de aula e foi mais utilizado pelo docente, do que pelos estudantes, tal como podemos verificar no gráfico 1. É de salientar que, ainda assim, a utilização do feedback, foi a categoria mais observada tanto pelo docente (39 referências), como pelos estudantes (12 referências), o que revela um elevado nível cognitivo dos assuntos abordados na sala de aula. Verificou-se que as interpelações, comentários ou respostas e análise de resultados experimentais, em atividades na sala de aula ou fora da sala de aula foi mais frequente (distribuição do feedback) pelo docente (38 referências) do que pelos estudantes (8 referências), o que é revelador de um ambiente agradável de sala de aula em que os estudantes estavam ativamente empenhados nas suas aprendizagens ativas.

Gráfico 1 - As referências do feedback, observadas na sala de aula, estudantes e docente.

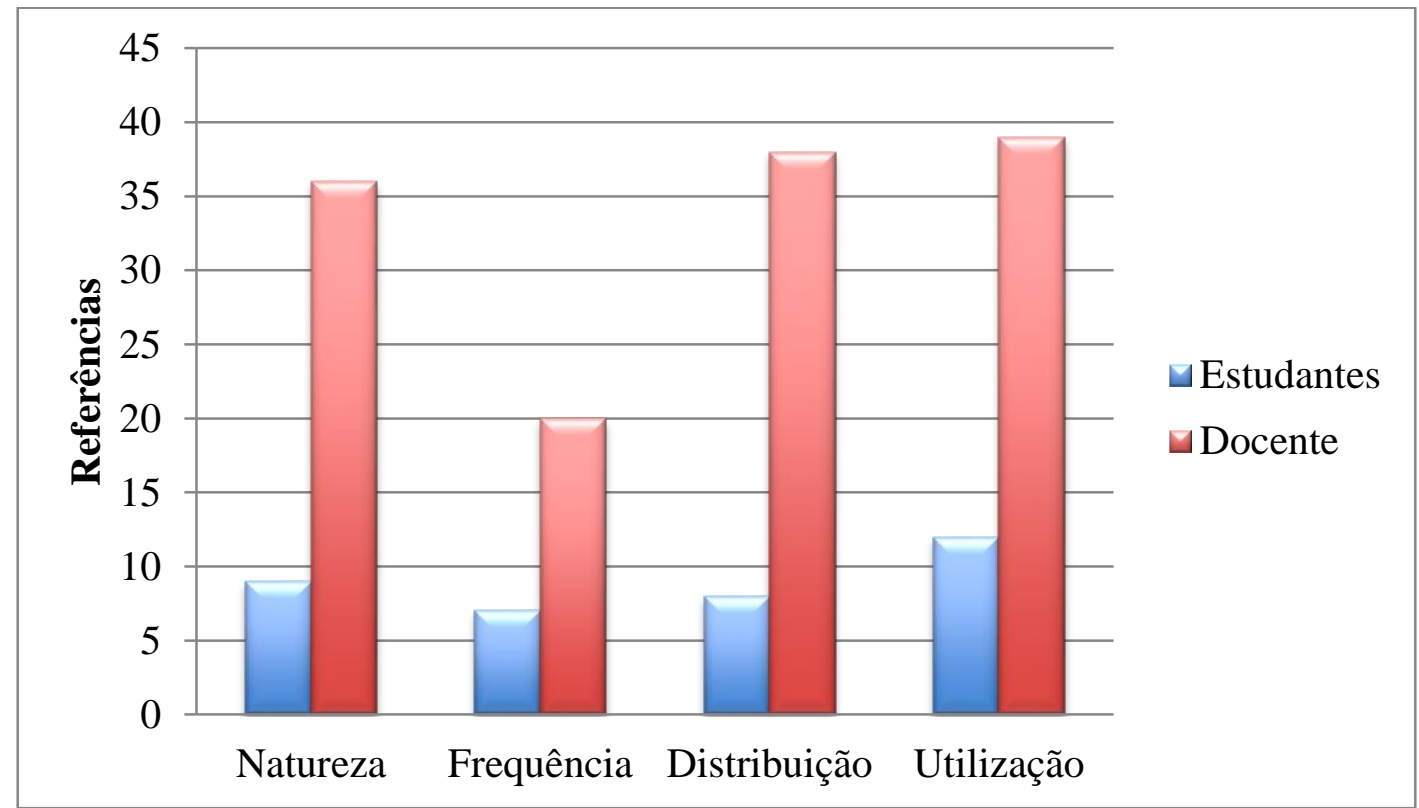

Fonte: dados da pesquisa

A natureza do feedback era claramente oral e informal (36 referências), observado em respostas geradas numa discussão para estimular a participação ou direcionar a discussão dos estudantes, o que permitiu manter sempre um elevado nível de estímulo à participação. Por parte dos estudantes, este foi muito menos observado (9 referências), uma vez que o trabalho de sala de aula era essencialmente em grupo o que dificultou a nossa observação, tendo sido a maior parte registado nas discussões entre os estudantes nas aulas de debate.

Os registos relativos à frequência do feedback foi também maior pelo docente (20 referências), contra 7 referências pelos estudantes. Em todo o caso, são indicadores do ambiente agradável, dinâmico e muito participativo, nos momentos de avaliação formativa existentes na sala de aula. 
O feedback contribuiu para a evolução da aprendizagem (STUFFLEABEAM \& SHINKFIELD, 1987; OLIVEIRA, 2000; ROLDÃO, 2003), tal como demonstra o comentário de um estudante, após a apresentação oral de uma tarefa de grupo, “... o professor ajuda-nos muito ... senti-me à vontade na apresentação ... porque não deixou que tivesse dúvidas, descobriu que temos dúvidas sem nós sabermos que as temos...”.

Os dados da observação e das entrevistas foram triangulados para lhes imprimir maior consistência. Assim, o feedback era interativo e construtivo, tal como se verifica numa afirmação do docente:

No contexto da aula tentar colocar-lhes questões, ouvi-los sobre as questões, de modo a perceber se, nesta interação eu podia perceber que, pelo menos com quem estava motivado para isso, interessado para isso, poderia entrar nesta interação mais bidirecional... (D).

O número elevado de estudantes limita esta tarefa:

É claro que com 70 alunos isto não é fácil. Isto é mais fácil quando se tem 5 ou 6. Apesar de tudo, eu acho que esta dinâmica de interação no contexto da aula para mim é importante. (D).

Os estudantes consideraram muito importante esta interação, tal como documenta a seguinte afirmação: "a professora estava sempre atenta se nós sabíamos ou não, colocava sempre questões pertinentes e se não soubéssemos responder ela ajudava sempre" (E).

O docente promovia o envolvimento dos estudantes na acomodação dos seus processos cognitivos, ajudando-os a desenvolver competências de autorregulação, ao mesmo tempo que promovia uma aprendizagem consistente,

\footnotetext{
Dar textos para eles lerem e perceberem o tema que ia ser tratado nas aulas e depois nas aulas trabalharem em grupo, algumas das aulas eu lembro-me que aquilo que eu fiz foi: eles pegavam nos artigos e eles próprios faziam questões sobre aqueles artigos que depois procurávamos responder no contexto da aula e, portanto, isto era torná-los mais ativos no processo de aprendizagem, também mais críticos, perceber o que é que eles saberiam, o que é que eles teriam dificuldade em compreender e depois a síntese final que eu tendia a fazer no final da aula. (D).
}

Os estudantes referiram que "como a professora está sempre a esclarecer os assuntos, nós conseguimos perceber se estamos a seguir a matéria, ou não, e até se estamos a saber" (E).

O docente criava ambientes de aprendizagem dinâmicos e não ameaçadores, estimulava a participação, a partilha, a colaboração, a exposição pessoal e a crítica construtiva, 
Pergunto o que é que eles acham, o que é que eles sabem, o que é que ... os desafia, e isto é ... eu acho que é uma forma de eu, enfim sem usar terminologia técnica que eu não conheço, é uma forma de eu tentar perceber se eles estão a acompanhar aquilo que eu estou a querer transmitir e se tenho capacidade para isso. (D).

Os estudantes referiram que "o trabalho de grupo ajudava-nos a partilhar os conhecimentos e a tornarmo-nos mais críticos" (E).

Os contextos de avaliação formativa, na sala de aula, proporcionado pelo docente teve o recurso ao feedback construtivo e interativo, embora o número elevado de estudantes tenha limitado um pouco a ação,

As vantagens têm a ver com envolver mais os alunos. Às vezes criava alguma confusão porque eles eram muitos, e... portanto, isso era uma desvantagem. Tendo em conta o número de alunos, este formato de aula ... enfim, exigiria menor número de alunos por aula e exigiria, se calhar, uma supervisão maior ... um docente para tantos alunos com esta modalidade não foi fácil e portanto acabou por, às vezes, em alguns momentos, o objetivo principal que era percorrer todos os grupos, todos os grupos apresentarem questões, todos os grupos apresentarem as sínteses, nem sempre foi possível. (D).

Ao colocar no centro o estudante, que constrói o seu conhecimento e monitoriza o desenvolvimento das suas competências, passou a ser uma estratégia de melhoria da aprendizagem, tal como referem os estudantes: "nas aulas de debate nós aprendíamos muito porque a matéria era desconstruída ou por nós ou pela professora e tornava-se tudo muito mais claro ou mais esclarecedor" (E), "num debate, eu consegui aprender a diferença entre um estudo de caso e um estudo etnográfico... estava a ser difícil, não percebia e depois tornou-se fácil" (E) e originou um incremento na motivação dos estudantes "nas aulas de discussão, apesar de saber que estávamos a ser avaliados, eu estava à vontade porque me sentia empenhada" (E).

\section{CONCLUSÕES}

O feedback foi usado, na UC observada, como estratégia de avaliação formativa, aumentou a motivação e a predisposição dos estudantes para o estudo dos conteúdos, resultando numa melhoria do seu desempenho (PERRENOUD, 1999; BIGGS, 2003; TORRANO \& GONZÁLEZ, 2004; ASKEW \& LODGE, 2000; HOUNSELL, 2007).

O feedback fez parte integrante e contínua da vida pedagógica da sala de aula observada, de modo interativo e construtivo, com privilégio do questionamento crítico ou estimulador e o apoio ou encorajamento. 
O feedback forneceu pontos de referência para orientar os estudantes que se aproximavam de um corpo relativamente não estruturado de conhecimento, de modo a reforçar a sua motivação intrínseca para aprender, assim como para estabelecerem padrões de conhecimento mais elevados.

O feedback proporcionou um ambiente de sala de aula dinâmico e os estudantes sentiram-se confortáveis e estimulados a colocar e tirar dúvidas.

Estes resultados sugerem que, em contextos similares, o recurso pelo docente e pelos estudantes, ao feedback construtivo e interativo deve ser uma estratégia de ensinoaprendizagem-avaliação, pois tem vantagens na motivação, na autorregulação e no desenvolvimento do pensamento crítico.

\section{REFERÊNCIAS}

ALARCÃO, I.; LEITÃO, A.; ROLDÃO, M. Prática pedagógica supervisionada e feedback formativo co-construtivo. Revista Brasileira de Formação de professores-RBFP, v. 3, n. 1, p. 02-29, 2009.

ALVES, M. P. Currículo e avaliação: uma perspectiva integrada. Porto: Porto, 2004.

AMADO, J.; COSTA, A. P.; CRUSOÉ, N. Análise de conteúdo. In: J. AMADO (Ed.), Manual de investigação qualitativa. Coimbra: Imprensa da Universidade de Coimbra, 2013.

ASKEW, S.; LODGE, C. Gifts. Ping-pong and loops: linking feedback and learning. In: ASKEW, S. (Ed.). Feedback for Learning. London: Routledge; Falmer, 2000. p. 1-17.

BARDIN, L. Análise de conteúdo. 5. ed. Lisboa: Edições 70, 2011.

BELL, B.; COWIE, B. Formative assessment and science education. Dordrecht, The Netherlands: Kluwer Academic Publishers, 2000.

BIGGS, J. Teaching for quality learning at university. Berkshire: Society for Research into Higher Education and Open University Press, 2003.

BIGGS, J.; TANG, C. Teaching for quality learning at university: what students does. 3. ed. Berkshire: MGraw-Hill; Society for Research into Higher Education and Open University Press, 2007.

BONWELL, C. C.; EISON, J. A. Active learning: Creating excitement in the classroom. Washington, DC: The George Washington University, 1991.

COSTA, António Pedro Dias da. Metodologia híbrida de desenvolvimento centrado no utilizador. 2012. 233 f. Tese (Doutorado) - Curso de Educação, Departamento de Comunicação e Arte, Universidade de Aveiro, Aveiro, 2012.

DREW, S. Student Perceptions of what helps them learn and develop. Higher Education, v. 6, n. 3, p. 309-331, 2001.

HADJI, C. A Avaliação, regras do jogo: das intenções aos instrumentos. Porto: Porto, 1994.

HIGGINS, R.; HARTLEY, P.; SKELTON, A. The conscientious consumer: reconsidering the role of

Comun. \& Inf., Goiânia, GO, v. 17, n. 2, p. 55-69, jul./dez. 2014 
assessment feedback in student learning. Studies in Higher Education, v. 27, n. 1, p. 53-64, 2002.

HOUNSELL, D. Towards more sustainable feedback to students. In: BOUD, D.; FALCHIKOV, N. (Eds.), Rethinking assessment in higher education: learning for thelonger term. London: Routledge, 2007. p. 101-113

FERNANDES, D. Para uma teoria da avaliação formativa. Revista Portuguesa de Educação, v. 19, n. 2, p. 21-50, 2006.

NICOL, D.; MACFARLANE-DICK, D. Formative assessment and self-regulated learning: a model and seven principles of good feedback practice. Studies in Higher Education, v. 31, n. 2, p. 199-218, 2006.

YORKE, Mantz. Formative assessment in higher education: moves towards theory and the enhancement of pedagogic practice. Higher Education, [s.i.], v. 45, n. 4, p.477-501, jun. 2003.

OLIVEIRA, Paulo José Coelho de. Ensino da física num curso superior de engenharia: na procura de estratégias promotoras de uma aprendizagem activa. 2009. $266 \mathrm{f}$. Tese (Doutorado) - Curso de Educação, Departamento de Didáctica e Tecnologia Educativa, Universidade de Aveiro, Aveiro, 2009.

NUÑO, Maria Ascensión Antón. Docencia universitaria: concepciones y evaluación de los aprendizajes: estudio de casos. 2012. 391 f. Tese (Doutorado) - Curso de Educación, Departamento de Ciencias de La Educación, Universidad de Burgos, Burgos, 2012.

PERRENOUD, P. Avaliação, da excelência à regulação das aprendizagens: entre duas lógicas. Porto Alegre: Artmed, 1999.

ROLDÃO, M. Gestão do currículo e avaliação de competências. Lisboa: Presença, 2003.

SOUZA, N. DE; COSTA, A.; MOREIRA, A. WEBQDA (Aveiro). Departamento de Educação da Universidade de Aveiro. Apresentação. 2014. Disponível em: <https://www.webqda.com/acerca/apresentacao/>.

STRUYVEN, K.; DOCHY, F.; JANSSENS, S. Students' perceptions about evaluation and assessment in higher education: a review. Assessment \& Evaluation in Higher Education, v. 30, n. 4, p. 331$347,2005$.

STUFFLEABEAM, D.; SHINKFIELD, A. Evaluación sistemática: guia teórica y práctica. Barcelona: Edicíones Paidós, 1987.

TORRANO, F.; GONZÁLEZ, M. Self-Regulated learning: current and futures directions. Electronic Journal of Research in Educational Psychology, v. 2, n. 1, p. 1-34, 2004.

Recebido em: 25/08/2014

Aceito em: 02/10/2014

Publicado em: 10/12/2014 